\title{
AVALIAÇÃO DA APRENDIZAGEM: CONCEPCÕES E PRÁTICA NA FORMAÇÃO DE PROFESSORES EM ANGOLA
}

FRANCISCO CALOIA ALFREDO

JUSSARA CRISTINA BARBOZA TORTELLA

\section{RESUMO}

O artigo apresenta resultados de uma pesquisa que visou a compreender a operacionalização da avaliação formativa na política de avaliação da aprendizagem para a formação de professores em Angola. Coletaram-se os dados por meio de questionários a professores e alunos, entrevistas semipadronizadas a professores e observação de aulas, analisados em categorias de conteúdo e em tabelas, discutidos sob a abordagem quanti-quali. Revela-se que turmas numerosas e a falta de condições de trabalho dificultam a prática avaliativa dos professores; os participantes são desfavoráveis à politica de avaliação por atribuir maior peso (60\%) à prova de escola e menor peso (40\%) às classificações atribuídas pelo professor; além do modelo de avaliação ser fortemente classificatório, os participantes se mostram favoráveis à avaliação formativa sempre classificatória.

PALAVRAS-CHAVE FORMAÇÃO DE PROFESSORES • AVALIAÇÃO FORMATIVA • ANGOLA. 


\section{RESUMEN}

El artículo presenta resultados de una investigación que buscó comprender la operacionalización de la evaluación formativa en la política de evaluación del aprendizaje para la formación de profesores en Angola. Los datos se recolectaron a través de cuestionarios a profesores y alumnos, entrevistas semiestructuradas a profesores $y$ observación de clases; se analizaron en categorías de contenido y en tablas y se discutieron según un enfoque cuantitativo-cualitativo. Se observó que grupos numerosos y la falta de condiciones de trabajo dificultan la práctica evaluativa de los docentes. Los participantes están en contra de la política de evaluación ya que le otorga un mayor peso (60\%) a la prueba de la escuela y un peso menor (40\%) a las calificaciones asignadas por los docentes. El modelo de evaluación es fuertemente clasificatorio y los participantes prefieren que la evaluación formativa sea siempre clasificatoria.

PALABRAS CLAVE FORMACIÓN DE PROFESORES • EVALUACIÓN FORMATIVA • ANGOLA.

\section{ABSTRACT}

This article presents the results of a study which aimed to understand the operation of formative assessment in the evaluation policy of teacher training in Angola. Data was collected through surveys responded by teachers and students, and five semi-standardized interviews. The data were analyzed by content categories and tables, and discussed according to a quantitative and qualitative approach. Results reveal that large classes and lack of working conditions hinder the evaluation practice of teachers; participants are disadvantaged in the evaluation policy which gives more weight (60\%) to the final test of the school year and lower weight (40\%) to the results of the assessments which occur during the training. Teachers and students are favorable to a formative assessment that is always classificatory. It appears that the evaluation model is strongly classificatory in all forms of assessment. The configuration of the evaluation policy needs to be reviewed, and there is a need to develop ongoing training in the assessment oflearning.

KEYWORDS TEACHER EDUCATION • FORMATIVE EVALUATION • ANGOLA. 


\section{INTRODUÇÃO}

Com o surgimento da segunda reforma no sistema educacional angolano em 2004, augurava-se superar falhas da primeira, de 1978: adequar a educação ao sistema de economia de mercado, favorecer a escolarização a todas as crianças em idade escolar, reduzir os índices de analfabetismo e aumentar a eficácia do sistema educativo. Para tal, o Ministério da Educação (MED) apontou quatro objetivos, a saber: 1. expandir a rede escolar; 2. melhorar a qualidade de ensino; 3 . reforçar a eficácia do sistema de educação; e 4. proporcionar a equidade do novo sistema de educação (ANGOLA, 2009b).

Os representantes do MED traçaram um plano faseado para a sua implementação com previsão de término em 2012, em que se avaliariam os currículos, o processo de ensino e aprendizagem, a formação de professores, a administração e a gestão dos materiais e das escolas.

É nesse contexto que realizamos uma pesquisa sobre a avaliação da aprendizagem, da qual resultou o presente texto, realizada no período de 2010 a 2012, numa das escolas angolanas de formação de professores de nível médio, com 
o objetivo de compreender a operacionalização da avaliação formativa, com referência à política de avaliação da aprendizagem implementada pelo MED em 2004, na formação de professores do $1^{\circ}$ Ciclo do Ensino Secundário. ${ }^{1}$

A perspectiva de abordagem da avaliação formativa nor1 No Brasil, corresponde ao fundamental 2. teadora neste artigo é a que coloca e releva o aspecto processual da aprendizagem mediante a diversidade de estratégias, flexibilização, reorganização e reorientação de atividades que promovam a aprendizagem do aluno, como mais adiante é sustentado.

A política de avaliação da aprendizagem da primeira reforma em Angola, diferencia-se da atual política, dentre outros aspectos, do ponto de vista da definição das modalidades, dos procedimentos de avaliação e responsabilização para a sua elaboração. Por exemplo, na primeira reforma eram as representações provinciais do MED que elaboravam os exames finais para as escolas, e as escolas podiam apenas produzir as avaliações e as provas que se realizavam durante o período letivo. Classificavam-se as avaliações na escala de 0 a 20 valores sem atribuição de porcentagem aos resultados que se obtivessem.

Com a atual reforma, implementada em 2004, a política de avaliação da aprendizagem confere às escolas a realização de todas as avaliaçõe, inclusive os exames ou as provas finais, mas aos resultados das classificações obtidas, quer das avaliações realizadas ao longo do ano letivo, designada classificação atribuída pelo professor, quer da avaliação final do ano letivo, designada classificação da prova de escola, atribui-se um valor percentual. Ou seja, de 2004 a 2009, atribuía-se à classificação feita pelo professor peso de $30 \%$, e à classificação da prova de escola, peso de $70 \%$. Nos últimos meses de 2009, o MED apresentou o sistema de avaliação das aprendizagens revisto em que o resultado das classificações obtidas ao longo do ano letivo tem $40 \%$ de peso e da prova de escola, $60 \%$ de peso.

Tal revisão não é explicitada nas diretrizes que a apregoam, porém especula-se que ela sucedeu dada a frequente reclamação e insatisfação dos atores do processo de ensino. Apesar disso, ao que parece, em nada se alterou no que se 
considera desvalorização das avaliações processuais. Isso quer dizer que, mesmo com a revisão do peso que se atribui às avaliações, a valorização tanto das avaliações formativas quanto das avaliações somativas, que realizam ao longo do ano letivo, não deixam de estar minimizadas independentemente de a avaliação formativa ser periódica.

De acordo com a política de avaliação da aprendizagem, a avaliação formativa, também designada avaliação contínua ou sistemática, é a que se realiza ao longo do processo de ensino e aprendizagem. É a avaliação de acompanhamento da aprendizagem permanente com vistas a proporcionar ambiente de interação entre o professor e os alunos no processo de ensino e aprendizagem. Por meio dessa avaliação o professor afere o aproveitamento do aluno classificando-o de forma numérica, diária, semanal e mensalmente (ANGOLA, 2005a).

As diretrizes da política ainda sugerem ao professor a prática da avaliação formativa, contínua ou sistemática, preferencialmente, avaliando o aluno com perguntas escritas no começo ou no fim de cada aula e com perguntas orais em qualquer momento do seu curso.

Esses procedimentos são justificados sob a necessidade de se acautelarem da subjetividade e de prováveis injustiças ao aluno durante as avaliações, pois alega-se que pode superar-se a subjetividade na avaliação fazendo-lhe poucas perguntas escritas. Assim, "para a avaliação contínua no início ou no fim da aula, o(a) professor(a) deve fazer não mais do que duas perguntas escritas para todos os alunos" (ANGOLA, 2005a, p. 14). Ainda ressalta-se que uma pergunta oral feita a determinado aluno pode ser repetida a outros mudando-se simplesmente a forma ou a estratégia de colocá-la, permitindo que considerável número de alunos seja avaliado durante a aula.

Já em relação à avaliação somativa, indica-se a realização de uma prova no fim de determinado ciclo de formação letiva com vistas a classificar, selecionar e certificar as aprendizagens do aluno (ANGOLA, 2003, 2005a).

As classificações das avaliações chamadas formativas, contínuas ou sistemáticas, que se realizam diária, semanal e mensalmente, atribuem-se na escala de 0 a 5 valores, diferentemente das classificações somativas cuja escala é de 0 a 
20 valores. Mas a média das avaliações formativas, designada MAC (média das avaliações contínuas), multiplica-se pela constante quatro (4), e adiciona-se ao seu resultado a prova do professor (classificada na escala de 0 a 20 valores), que dividido por dois gera o quociente que se considera a classificação trimestral do aluno. Ao multiplicar-se a MAC pela constante, pretende-se equipará-la à escala das classificações das avaliações somativas. Esses procedimentos são realizados em todos os trimestres letivos (ANGOLA, 2003, 2005a, 2006, 2009a, 2009b).

A classificação na escala de 0 a 20 apresenta as seguintes qualificações: de 0 a 4 valores, considera-se má ou pouca progressão do aluno; de 5 a 9, classificação medíocre ou de progressão muito lenta; de 10 a 13, classificação de suficiente progressão; de 14 a 17, classificação de boa progressão; e de 18 a 20 valores, classificação muito boa com segurança na aprendizagem.

A base conceitual da avaliação da aprendizagem, expressa na política de avaliação da aprendizagem, tem como referência os conceitos de Beeby (s/d) e Stuffbean (1998). O primeiro autor define a avaliação da aprendizagem como "um processo de recolha e interpretação de informações que implicam juízos de valores, com vista à tomada de decisões” (BEEBY, s/d apud ANGOLA, 2005a, p. 7, 2005b, p. 5, 2006, p. 8). Para o segundo, praticamente, na mesma direção do autor anterior, a avaliação é

[...] o processo de identificar, obter e proporcionar informação útil e descritiva acerca do valor e do mérito, da planificação, da realização e do impacto de um objectivo determinado com o fim de servir de guia para a tomada de decisões, para solucionar os problemas de responsabilidade e para promover a compreensão dos fenômenos implicados. (STUFFBEAN, 1998 apud ANGOLA, 2003, p. 6)

As concepções de avaliação dos autores citados parecem evidenciar a sua dimensão processual na valorização da aprendizagem dos alunos na medida em que são tomadas com base na interpretação das suas dificuldades. Assim, os conceitos que são adotados manifestam propósitos da 
avaliação a serviço do processo de ensino e da aprendizagem, no qual se realçam as características da realidade em que incide a prática avaliativa. A adoção desses propósitos parece não passar da intenção de querer propor-se uma avaliação que promova realmente a aprendizagem, pois a configuração da política de avaliação da aprendizagem é fortemente arraigada à medição e à classificação. Por conseguinte, a intenção da avaliação está perdida no conjunto de procedimentos apresentados sem que sejam tidas em conta, por exemplo, a coerência de variáveis, como o tempo que o professor dispõe para avaliar, as condições de trabalho e outras atividades administrativas (FREITAS et al., 2011).

Além das avaliações a que todos os alunos são submetidos durante e no fim do ano letivo, ainda existem os chamados Exames de Aptidão Profissional, que se aplicam apenas a alunos da $13^{\mathrm{a}}$ série. Esses exames visam avaliar os objetivos e os conteúdos, considerados fundamentais, desenvolvidos ao longo dos quatro anos de formação do aluno, futuro professor, especificamente nas disciplinas de Formação Profissional de Prática Pedagógica; Seminários; Metodologias de Ensino e Estágios Pedagógicos. Os exames têm como objetivos classificar, selecionar e certificar as aprendizagens dos alunos (ANGOLA, 2005c).

\section{FUNDAMENTAÇÃO TEÓRICA}

Geralmente a abordagem da avaliação formativa é atrelada à concepção de Benjamim Bloom ao referir-se à que ocorre no fim de determinando ciclo de formação com vistas a alcançar-se objetivos delineados (FERNANDES, 2006, 2009), ou à proposta por Linda Allal e Lucie Lopez (2005), que amplia a primeira concepção ao pôr em relevo a tríade das regulações: retroativa, interativa e proactiva. Na discussão dos dados da pesquisa adotou-se esta última proposta.

Para Allal (1986, p. 176), a concepção de avaliação formativa de Bloom representa "componente essencial na realização de uma estratégia de pedagogia de mestria [...] ou de qualquer outra tentativa de individualização do ensino", 
incompleta para uma perspectiva psico e sociopedagógica da aprendizagem que visa a estabelecer características e finalidades de regulação da avaliação para a aprendizagem. O propósito da avaliação formativa é de "assegurar uma regulação dos processos de formação, quer dizer, de fornecer informações detalhadas sobre o processo e/ou os resultados de aprendizagem do aluno a fim de permitir uma adaptação das atividades de ensino/aprendizagem" (ALLAL s/d apud DE LANDSHEERE, 1997, p. 5, tradução livre), o que signfica, segundo PetitJean (1984, p. 5-20 apud LANDSHEERE, 1997, p. 5, tradução livre), que “a questão essencial da avaliação formativa [é de tornar] [...] o aluno ator da sua aprendizagem”. Nesse sentido, define-se a avaliação formativa como

[...] um processo de avaliação contínua tendo por objetivo assegurar a progressão de cada indivíduo no prosseguimento da aprendizagem, com a intenção de modificar a situação da aprendizagem ou o ritmo desta progressão, para proporcionar (em caso de necessidade) melhorias ou correções apropriadas. (SCALLON, 2010, p. 10, nossa tradução)

A concepção de avaliação formativa que amplia a concepção de Bloom incide sob a perspectiva socioconstrutivista que, além de destacar o âmbito das regulações - sobretudo das interações entre alunos na sala de aula -, justifica-se pela ênfase na "importância das condições sociais propícias para a construção dos conhecimentos. [...] o conhecimento é construído graças à ação exercida sobre o meio, é a atividade estruturante do sujeito que fundamenta o seu desenvolvimento cognitivo" (HADJI, 2011, p. 41).

Talbot (2009, p. 8) considera três situações a evidenciar na prática da avaliação formativa:

\footnotetext{
A situação obstáculo relativa ao conteúdo de ensino, a atividade necessária do aluno para ultrapassar o conflito cognitivo engendrado por este obstáculo e a mediação permanente do professor com vistas a ajudar, guiar, assegurar os alunos ao longo da construção de seus conhecimentos, notadamente àqueles que se mostrem mais frágeis. (nossa tradução)
} 
A criação de diversas situações de atividades configura o sentido a essas direções para uma avaliação formativa. Assim, a proposta ampliada da avaliação formativa resume-se de acordo com o quadro que se segue.

QUADRO 1 - Concepção inicial de Bloom vs. concepção ampliada da avaliação formativa

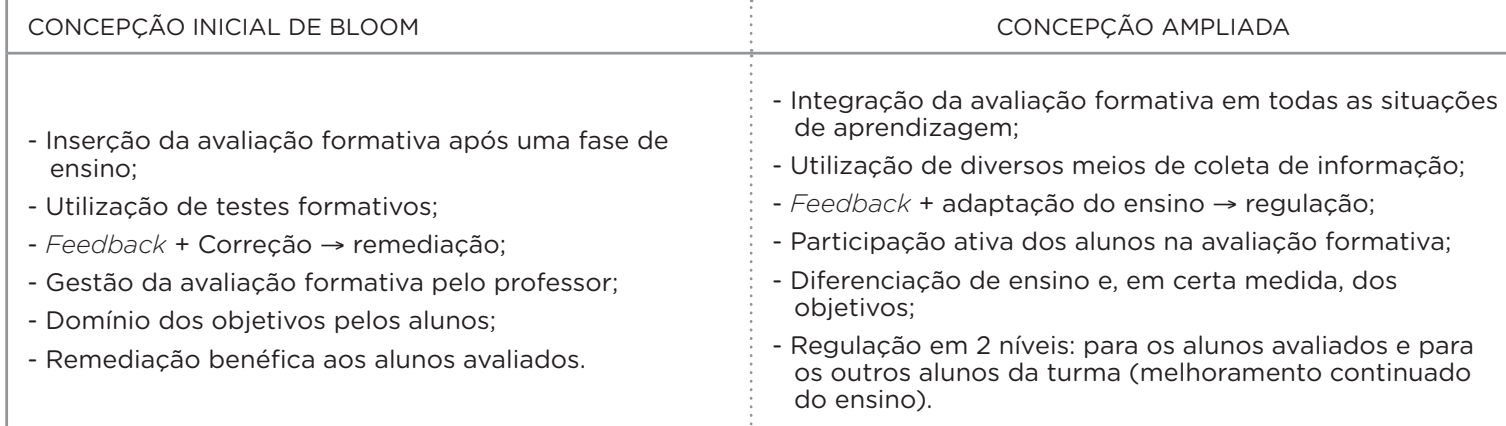

Fonte: Allal e Lopez (2005).

Como se observa no quadro anterior, a perspectiva da avaliação formativa na contemporaneidade mobiliza um conjunto de processos a serem colocados em evidência tanto pelo aluno como pelo professor no decorrer do processo de ensino e aprendizagem.

\section{MÉTODO}

A pesquisa caracteriza-se como descritiva por explorar situações de acontecimentos ou fenômenos (SAMPIERI et al., 2006).

Partindo do objetivo geral de compreender a configuração da avaliação formativa na formação de futuros professores do $1^{\circ}$ Ciclo do Ensino Secundário, tendo como referência a política de avaliação da aprendizagem proposta pelo Ministério da Educação de Angola, a pesquisa tomou como objetivos específicos os seguintes: 1. estudar a legislação da Reforma Educativa e da Formação de Professores do Ensino Básico, implementada pelo Ministério da Educação de Angola; 2. analisar a política de avaliação da aprendizagem para a formação de futuros professores; 3. compreender os posicionamentos dos professores (formadores) e alunos (futuros professores) da Escola de Formação de Professores sobre a política de avaliação da aprendizagem; 
4. identificar as concepções e as práticas da avaliação formativa no cotidiano escolar dos professores e alunos.

Para atingir os objetivos estabelecidos, utilizamos instrumentos coerentes com a pesquisa descritiva, a saber: análise de documentos, questionários, entrevistas e observação de situações ou fenômenos (BARROS; LEHFELD, 1990). Participaram do estudo 283 alunos, futuros professores, da $10^{\mathrm{a}}$ à $13^{\mathrm{a}}$ série, e 23 professores, formadores. Após a assinatura do Termo de Consentimento Livre e Esclarecido, os participantes responderam ao questionário composto, respectivamente por 21 perguntas para os professores e 19 para os alunos, entre dicotômicas e mistas. Foram entrevistados com base em questões semiestruturadas cinco professores, cujos nomes que aqui se utilizam são fictícios; destes, dois também responderam ao questionário. Os entrevistados foram indicados ao pesquisador por serem os que mais promovem discussões sobre a reforma educacional no seio dos colegas, além de possuírem experiência profissional acima de vinte anos. Observaram-se cinco aulas com 50 minutos cada, de professores que se mostraram disponíveis. Destas, uma foi na disciplina de História na $13^{\mathrm{a}}$ série, na qual no dia da observação os alunos realizavam atividades em pequenos grupos; uma aula dupla expositiva também de História, mas na $10^{a}$ série e com outro professor; duas aulas de Biologia em turmas e professores diferentes na $12^{\mathrm{a}}$ série. A primeira era de revisão da matéria para a prova do professor e a segunda, aula expositiva da matéria, também de professores diferentes.

Os professores participantes da pesquisa têm formação, alguns concluída em nível de bacharel, licenciatura e mestrado em Ciências da Educação, outros em curso.

No que se refere aos documentos analisados relativos à política de avaliação da aprendizagem, os mesmos compõem o conjunto de documentos orientadores da Reforma Educativa de 2004, assentes na Lei n. 13/01 - Lei de Base do Sistema de Educação, notadamente o Sistema de Avaliação das Aprendizagens para a Formação de Professores, Metodologia de Avaliação no Contexto Escolar, Regulamento para os Exames de Aptidão Profissional, Guia Metodológico 
para Avaliação das Aprendizagens e Manual de Apoio ao Sistema de Avaliação das Aprendizagens, $2^{\circ}$ Ciclo do Ensino Secundário: reforma curricular.

A análise desses documentos foi realizada com base em um roteiro previamente elaborado que contempla as modalidades, a estrutura e os procedimentos propostos na prática avaliativa dos professores.

Os dados foram codificados de acordo com a sua natureza e discutidos de forma triangulada. Para tabular os dados quantitativos utilizou-se a planilha eletrônica do programa Microsoft Excel 2010, e a análise dos dados qualitativos ou não numéricos foi realizada com suporte do software WebQDA (Web Qualitative Data Analysis), que permite sua utilização em qualquer fase da pesquisa (NERI DE SOUZA; MOREIRA, 2011).

\section{ANÁLISE E DISCUSSÃO DOS RESULTADOS}

Exploram-se, no presente artigo, as posições dos professores, formadores, e dos alunos, futuros professores, em relação aos aspectos da política de avaliação da aprendizagem; o seu impacto na formação de professores do $1^{\circ}$ Ciclo do Ensino Secundário; a forma como os professores avaliam quando as turmas são numerosas; e as concepções sobre a avaliação formativa.

\section{POSIÇÃO DOS PROFESSORES}

Os professores responderam a seis questões relacionadas aos aspectos específicos da política, conforme a tabela com as legendas que correspondem a: (Questão 16) - atribuir maior peso à Prova de escola; (Questão 17) - atribuir menor peso às avaliações formativas (contínuas ou sistemáticas) e à Prova do Professor; (Questão18) - atribuir notas às avaliações formativas (contínuas ou sistemáticas); (Questão19) - avaliar continuamente os alunos; (Questão 20) - utilizar Cadernetas padronizadas nas avaliações diárias; e (Questão 21) - realizar Exames de Aptidão Profissional. Ressalta-se que os professores poderiam, para essas questões, além de assinalar as alternativas propostas, deixar comentários que completassem seu posicionamento. 
TABELA 1 - Posição dos professores sobre a política de avaliação da aprendizagem

\begin{tabular}{l|c|c|c|c|c|c}
\hline & QUESTÃO 16 & QUESTÃO 17 & QUESTÃO 18 & QUESTÃO 19 & QUESTÃO 20 & QUESTÃO 21 \\
\hline Concorda completamente & $20 \%$ & $15 \%$ & $55 \%$ & $55 \%$ & $55 \%$ & $50 \%$ \\
\hline Concorda pouco & $10 \%$ & $0 \%$ & $20 \%$ & $15 \%$ & $15 \%$ & $5 \%$ \\
\hline Discorda completamente & $65 \%$ & $50 \%$ & $0 \%$ & $0 \%$ & $20 \%$ & $5 \%$ \\
\hline Discorda um pouco & $0 \%$ & $15 \%$ & $10 \%$ & $5 \%$ & $0 \%$ & $15 \%$ \\
\hline Não respondidas & $5 \%$ & $20 \%$ & $15 \%$ & $25 \%$ & $10 \%$ & $25 \%$ \\
\hline
\end{tabular}

Fonte: Elaboração dos autores.

A maior parte dos professores é completamente desfavorável à atribuição de maior peso à Prova de escola realizada apenas no final do ano letivo, e também completamente desfavorável ao peso que se atribui aos resultados das classificações do professor.

Observa-se que a maior parte dos professores é completamente favorável à atribuição de valor classificatório à avaliação formativa, à necessidade de se avaliar continuamente o aluno, à utilização de Cadernetas padronizadas e à realização de Exames de Aptidão Profissional. Se por um lado, maior parte dos professores mostrar-se discordante com o peso que se atribui às avaliações decorrentes ao longo do ano letivo, mas de acordo com a realização de avaliações contínuas e de Exames de Aptidão Profissional, por outro, é nestes aspectos em que menos os professores se posicionam.

Não parece que havendo posições desfavoráveis em relação ao peso atribuído ao resultado das avaliações que se realizam ao longo do ano letivo signifique a adesão à avaliação formativa menos classificatória, pois as concepções apresentadas a esse respeito e a configuração na política de avaliação da aprendizagem conferem sempre valor classificatório a essa modalidade de avaliação. Provavelmente, o que se evidencia é o reconhecimento da importância de se ter um número maior de avaliações durante o ano letivo do que somente ao seu término.

Assim, admitir também que as avaliações realizadas ao longo do ano letivo são menos valorizadas em relação àquela que se aplica no final do ano letivo pode revelar a importância 
que se dá às atividades desenvolvidas ao longo do processo de ensino e aprendizagem, mas não, necessariamente, significar a desconstrução de uma cultura avaliativa de mensuração ou de classificação.

No que se refere à posição favorável sobre a utilização de Cadernetas padronizadas, supõe-se que os professores as apoiam em função da utilidade que elas têm para as anotações das classificações numéricas realizadas diariamente na sala de aula. Nesse sentido, as diretrizes sugerem que as Cadernetas sirvam para o controle das notas dos alunos, uma vez que, além de serem utilizadas para os registros, também podem servir para melhor organizar e realizar os cálculos aritméticos das médias dos alunos, assim como ajudar-lhes no acompanhamento escolar.

Os professores não apresentam uma única posição quanto aos Exames de Aptidão Profissional. A maior parte revela estar completamente de acordo com a sua realização, quando a minoria revela concordar pouco, discordar completamente e discordar um pouco. Destes últimos, verificam-se, nos questionários, comentários que enfatizam a posição da parcial e da completa discordância sobre a realização desses exames.

Os professores afirmam, por um lado, que os exames não proporcionam sentido à formação dos futuros professores porque os alunos, principalmente os finalistas de curso, ao longo da formação, trabalham com os conteúdos exigidos nos referidos exames. Por outro lado, sugerem que esses exames avaliem "a prática do estudante, uma vez que este esteve empenhado no estágio".

Independentemente de se verificar comentários opostos à maior parte dos professores que se diz favorável à realização desses exames, essas opiniões mostram a necessidade de se valorizarem as matérias desenvolvidas ao longo da formação, além de mostrarem que a sua realização seja apenas de forma prática. Os alunos, futuros professores, também fizeram uma apreciação sobre a política, conforme o ponto a seguir.

\section{POSIÇÃO DOS ALUNOS}

Com a mesma legenda utilizada na tabela anterior, segue-se a análise da política de avaliação na perspectiva dos alunos. 
TABELA 2 - Posição dos alunos sobre a política de avaliação da aprendizagem

\begin{tabular}{|c|c|c|c|c|c|c|}
\hline & QUESTÃO 16 & QUESTÃO 17 & QUESTÃO 18 & QUESTÃO 19 & QUESTÃO 20 & QUESTÃO 21 \\
\hline Concorda completamente & $36 \%$ & $19 \%$ & $65 \%$ & $55 \%$ & $48 \%$ & $26 \%$ \\
\hline Concorda pouco & $22 \%$ & $15 \%$ & $10 \%$ & $16 \%$ & $14 \%$ & $12 \%$ \\
\hline Discorda completamente & $21 \%$ & $31 \%$ & $3 \%$ & $3 \%$ & $4 \%$ & $17 \%$ \\
\hline Discorda um pouco & $8 \%$ & $12 \%$ & $2 \%$ & $2 \%$ & $5 \%$ & $6 \%$ \\
\hline Não tem conhecimento & $4 \%$ & $4 \%$ & $1 \%$ & $3 \%$ & $8 \%$ & $16 \%$ \\
\hline Não respondidas & $9 \%$ & $19 \%$ & $19 \%$ & $21 \%$ & $21 \%$ & $23 \%$ \\
\hline
\end{tabular}

Fonte: Elaboração dos autores.

Embora não estando a maioria dos alunos favorável à atribuição de maior peso à Prova de escola, observa-se existir maior índice de alunos completamente favoráveis à atribuição do maior peso das avaliações a essa prova, assim como verifica-se maior índice da representatividade dos alunos completamente desfavoráveis ao peso que se atribui ao resultado das avaliações realizadas ao longo do ano acadêmico ou à classificação atribuída pelo professor. Mas também se constata, em relação à distribuição do peso às avaliações no geral, a ambiguidade nas suas posições. Ou seja, os alunos evidenciam que se valorize a Prova de escola e ao mesmo tempo as avaliações que se realizam ao longo do ano letivo. O que pode significar que não deve haver diferença entre o valor que se atribui aos resultados da prova final e ao valor atribuído aos resultados das avaliações ao longo do ano letivo.

Também se observa, praticamente de todos os alunos, a manifestação de que a avaliação formativa tenha atribuição de uma nota; que se avalie continuamente o próprio aluno; e que os professores utilizem Cadernetas padronizadas de registros.

No que se refere aos Exames de Aptidão Profissional, não se verifica acordo na posição da maior parte dos alunos, porém há maior índice de representatividade de alunos que concordam completamente com a sua realização. Verifica-se 
também, dentre os aspectos da política de avaliação da aprendizagem, que a Caderneta padronizada e os Exames de Aptidão Profissional são os elementos cuja operacionalização seja mais desconhecida pelos alunos.

Se, por um lado, os resultados obtidos referentes à política de avaliação da aprendizagem apontam que ainda há alunos pouco informados ou mesmo desinformados sobre o seu funcionamento, por outro lado, supõe-se haver pouca socialização dos documentos e dos materiais a ponto de serem estudados criticamente.

Sendo a Caderneta e os Exames de Aptidão Profissional aspectos da política de avaliação da aprendizagem mais evidentes de que os alunos desconhecem sua operacionalização, em relação à primeira, estranha-se tal desconhecimento, porquanto ela é utilizada desde os níveis de ensino anterior ao médio. Em relação ao segundo, a sua utilização ocorre unicamente na série finalista do curso e, provavelmente, o fato de os exames serem aplicados em momento específico da formação do futuro professor justifica, sobretudo, o desconhecimento da sua operacionalização aos alunos do primeiro ano. Com efeito, para os alunos pré-finalistas e finalistas de curso, manifestar tal desconhecimento acentua a hipótese da insuficiente fluidez na socialização dos documentos e matérias inerentes à própria reforma curricular.

Mesmo havendo diferenças consideráveis entre as amostragens de professores e dos alunos, tais diferenças não inibem a possibilidade de ser comparada a tendência dos resultados obtidos em ambos os grupos sob pretensão de não se pôr, necessariamente, em relevo o aspecto quantitativo, mas, com base nele, perceber-se a valorização atribuída aos aspectos enfocados na política de avaliação da aprendizagem para a formação de professores. Assim, relativamente à atribuição de maior peso à Prova de escola, a maior parte dos professores (65\%) é completamente desfavorável, ao passo que os alunos se alinham na posição contrária à dos professores. O que se verifica em relação aos alunos é haver maior índice (36\%) a revelar-se completamente favorável à atribuição de maior peso à Prova de escola. 
Quanto ao menor peso que se atribui ao resultado das avaliações realizadas ao longo do ano letivo, tanto os professores (50\%) quanto os alunos revelam não concordar, mas, para os alunos, essa postura representa $31 \%$, o que corresponde ao maior índice das suas representações. Tanto os professores (55\%) quanto os alunos (65\%) são completamente favoráveis à atribuição de uma classificação numérica à avaliação formativa.

O igual valor percentual (55\%) de professores e alunos revela-se completamente favorável com a realização de avalições contínuas ao aluno e utilização de cadernetas padronizadas de registro de notas. Relativamente à realização de Exames de Aptidão Profissional, é parte dos professores (50\%) que mostra estar completamente favorável, ao passo que dos alunos verifica-se maior índice (26\%) com a mesma perspectiva dos professores. Com isso, podemos perceber o impacto da política em análise, que passamos a seguir a refletir.

\section{IMPACTO DA POLÍTICA DE AVALIAÇÃO DA APRENDIZAGEM}

As concepções dos professores e dos alunos, identificadas com base nos questionários e nas entrevistas, às vezes convergem em pontos que lhes parecem negativos e positivos sobre a política de avaliação da aprendizagem. Por exemplo, ambos mostram-se desfavoráveis ao peso que se atribui ao resultado das avaliações realizadas durante o ano letivo, mas consideram positivo o fato de classificar-se e atribuir-se nota à avaliação formativa.

O professor Edilson é dos que consideram a política de avaliação da aprendizagem com impacto negativo,

[...] porque o que está escrito praticamente na teoria não temos aplicado tendo em conta que a realidade faz com que nós não podemos praticamente aplicar aquilo que está instituído. Isto porque, praticamente, entramos em depressiva porque as condições com que nós avaliamos os alunos não são as mais adequadas, tendo em conta o número pletórico de aluno, faz com que o sistema de avaliação não seja assim tão eficiente, seja apenas um sistema avaliativo parcial. 
Nessa linha de pensamento, verifica-se o argumento do professor Eliandro, que considera a implementação da política de avaliação uma ação que não levou em conta a realidade das escolas angolanas. Com efeito, a avaliação que se exige do professor está deslocada da realidade das escolas. O interlocutor reitera o elevado número de alunos por turma como estando na base de uma das insatisfações dos professores no processo de avaliação na sala de aula. Atesta que a política de avaliação “está um pouco deslocada a sua materialização teoria e prática. No sistema da reforma, quero crer que a nossa realidade é outra, o número de aluno é muito grande e, então, muitas vezes, para aplicar a avaliação, tem sido muito complicado".

Verifica-se que a insatisfação desses interlocutores, direta ou indiretamente, contrapõe ao que normalmente a reforma anuncia, que é favorecer maior qualidade ao sistema educacional. Por conseguinte as consequências negativas das implicações da reforma e da forma como se operacionaliza, muitas vezes, são imputadas, exclusivamente, ao professor por ser o que lida com a realidade carente de melhorias, quando, na verdade, ofuscam-se as questões menos dependentes da sua atuação.

Para o professor Ernesto, o sistema de avaliação da aprendizagem é bom, porquanto o aluno, por meio das avaliações formativas, percebe o seu empenho e passa a conhecer diariamente as suas notas.

Apesar das variáveis anteriormente focalizadas pelos professores, como as que dificultam a prática da avaliação, para a maior parte dos alunos $\left(59 \%\right.$ da $10^{\mathrm{a}}$ série, $57 \%$ da $11^{\mathrm{a}}$ série, $57 \%$ da $12^{\text {a }}$ série e $63 \%$ da $13^{\mathrm{a}}$ série) a política de avaliação contribui muito para melhorar as suas aprendizagens.

Para alguns alunos, a política de avaliação das aprendizagens em pouco ou em nada contribuí para o melhoramento de suas aprendizagens. Por exemplo, um aluno da $10^{\mathrm{a}}$ série afirma que as avaliações realizadas durante as aulas valorizam o aproveitamento do aluno, ao passo que a Prova de escola valoriza menos; eventuais dificuldades que podem impedir o aluno de obter boa nota na Prova de escola não são tidas em conta na forma como são valorizadas as notas das avaliações. 
$\mathrm{Na} 11^{\mathrm{a}}$ série os alunos ressaltam que a reforma devia ser rígida no controle da frequênci, pois muitos deles já se deram conta de que não precisam assistir regulamente às aulas, ou mesmo não precisam ser diariamente avaliados porque há alunos que são aprovados apenas fazendo a Prova de escola. Ainda afirmam que a forma como são avaliados faz com que eles se preocupem menos com a matéria nos dois primeiros trimestres letivos, visto que o valor das avaliações está no último trimestre, pelo que os três trimestres deviam ter o mesmo peso nas avaliações, de maneira que os alunos se dediquem mais aos estudos durante todo o ano letivo. Assim,

[...] gostaria que o sistema de avaliação fosse um pouco alterado porque, quando se atribui maior percentagem, eu acho um exagero. $O$ aluno se esforça durante o ano e pode ter recaída no fim, por isso eu acho que as avaliações contínuas deviam valer mais, e as provas do professor e de escola seriam apenas para complementar. (Aluno da $\mathbf{1 1}^{a}$ série)

$\mathrm{Na} 12^{\mathrm{a}}$ série, além de identificarem-se afirmações do tipo: "este tipo de avaliação enriquece, mas também prejudica. Sugeria que todos os professores pudessem dar notas a todas as avaliações, porque incentivam os alunos a estudar rumo ao desenvolvimento e não à corrupção", os alunos alinham com a posição das séries anteriores.

É patente nas palavras dos alunos a pretensão de uma política de avaliação que não descure detalhes do seu desempenho na aprendizagem ao longo do processo de ensino e aprendizagem, mesmo tendo uma prática avaliativa que culmine com a atribuição de nota. Assim, pode considerar-se que os alunos almejam uma política de avaliação que valorize o seu esforço empreendido ao longo da formação. Ademais, entende-se que as representações quantitativas podem ser insuficientes para esclarecer-se ou evidenciar-se uma compreensão da dimensão da política de avaliação no melhoramento da aprendizagem. Tanto os comentários apresentados quanto os dados percentuais podem subsidiar a reflexão sobre a prática e a política de avaliação da aprendizagem. O número de aluno por turma e as concepções e as práticas da avaliação na sala de aula são explorados nos pontos subsequentes. 


\section{NÚMERO DE ALUNO POR TURMA}

Verificou-se que 30\% dos professores têm de 46 a 65 alunos por turma; 25\% dos professores têm de 35 a 45 alunos; 15\% têm de 66 a 75 alunos; outros 15\% têm de 86 a 95 alunos; $10 \%$ têm de 76 a 85 alunos, e 5\% dos professores têm de 96 a 100 alunos por turma.

Ao que se constatou, a distribuição do número de alunos não obedece a nenhum critério. O professor pode ter turmas muito ou pouco numerosa e possuir carga horária de 20 horas semanais, de acordo com o estatuto do subsistema de formação de professores.

Nos pronunciamentos dos professores, ostensivamente, identificam-se alegações de que o elevado número de alunos por turma influencia bastante para o insucesso da organização e da operacionalização da avaliação formativa; todavia, em rigor, os professores não fundamentam tal enunciado.

Os professores afirmam que, na época em que aplicam, classificam, corrigem as provas e têm de apresentar os respectivos resultados às coordenações de disciplinas, encontram dificuldades no cumprimento dos prazos estabelecidos no calendário escolar.

Afirmam que, para realizarem uma avaliação quer escrita quer oral, requer-se diminuir o número de alunos por turma e ter mais tempo de aula de modo a que os alunos sejam corretamente avaliados porque alegam ser "extremamente complicado dar aulas e ao mesmo tempo avaliar todos os alunos oralmente em todas as aulas; Não permite o acompanhamento de todos os alunos numa só aula; [...] o professor não tem controle exacto da turma quanto às capacidades individuais".

Questionado sobre o número de alunos desejável por turma, apresentaram opiniões diferentes que foram enquadradas em três grupos: o primeiro, e maioritário, propõe turmas de 20 a 30 alunos; o segundo, de 30 a 35 alunos e o terceiro, de 40 a 45 alunos.

As razões que sustentam as três propostas são similares. Os professores afirmam que, com a redução do número de alunos por turma, facilitaria a avaliação de todos os alunos em cada aula e, ao mesmo tempo, facilitaria o acompanhamento do desempenho individual; facilitaria ao 
professor corrigir possíveis erros ortográficos de cada aluno; o professor conheceria melhor os alunos e, com rigor, poderia alcançar os objetivos que se pretendessem, porque prestaria atenção a todos os alunos; o professor teria, também, maior contato com eles.

Das observações realizadas nas aulas, à exceção de uma turma, as outras apresentavam número considerável de absentismo de alunos e eram avaliados em pequenos grupos ou no geral com perguntas do professor e respostas dos alunos.

$\mathrm{O}$ mar de dificuldades no qual navegam os atores do processo de ensino e aprendizagem em Angola, e tendo em conta a distância entre a realidade e o desejável manifestado pelos professores, também aponta para que se explorem a concepção e os contornos sobre a avaliação formativa, como se assinala no próximo ponto.

\section{CONCEPÇÕES SOBRE A AVALIAÇÃO FORMATIVA}

Atendendo aos dados obtidos nos questionários, os professores entendem a avaliação da aprendizagem como avaliação somativa, prática sistemática e contínua da avaliação; verificação do nível de assimilação dos alunos; e prática contínua que visa medir com auxílio de instrumentos. Há quem defina a avaliação da aprendizagem como atividade subjetiva distante de corresponder à realidade sobre a qual se aplica e de não preparar os alunos.

As concepções sobre a avaliação da aprendizagem dos professores, em grande parte, não refletem diretamente os conceitos da avaliação propostos nas diretrizes da política de avaliação da aprendizagem, mas refletem, principalmente, a realidade cotidiana deles tomada da e com a prática de avaliação à luz da organização e procedimentos estabelecidos pela política de avaliação.

Centrando-se na avaliação formativa, o professor Eurico entende que ela apresenta faceta abrangente no sentido de que, além de visar conteúdos, integra diferentes conhecimentos que valorizam as competências e experiências do aluno, adequando-as à vida. 
Para o professor Evaristo, falar-se da avaliação formativa deve-se partir da sua distinção com a avaliação somativa, pois considera haver um elemento comum em ambas as modalidades. $\mathrm{O}$ interlocutor afirma que, quando se realiza a avaliação sistemática, esta também pode ser formativa.

O professor Eliandro, adentrando à realidade da própria escola, considera difícil colocar em prática os pressupostos da avaliação formativa por implicarem sequências permanentes, sem descurar a preocupação com o número de alunos por turma e o tempo disponível para avaliá-los. Assim, torna-se necessário, segundo o interlocutor, encontrarem-se estratégias diversificadas de avaliação como aquelas em que o professor faz perguntas escritas a toda a turma.

Segundo o professor Evaristo, em Angola, as avaliações aparentam promover a aprendizagem quando na realidade têm finalidade última definir se o aluno aprova ou reprova de série, ou se termina ou não a formação média. "E parece que nós interessamo-nos mais com este elemento de chegar ao fim, dizer que tenho 50\%, 60\% de aproveitamento. Portanto, este elemento só vê a partir da avaliação somativa e aí é onde se vai identificar". Para efeitos pedagógicos, sugere que as classificações sejam em conceito, pois lhe parece ser mais fácil converter a classificação conceitual à classificação numérica, sob alegação de que a primeira possibilidade facilita mais para o professor classificar o aluno.

Na perspectiva dos alunos a avaliação formativa é a que os professores realizam diariamente na sala de aula com propósito final de lhes atribuir nota como, por exemplo, desfilam seus comentários:

1. Avaliação formativa é para o aluno sempre vir preparado na escola porque há aluno que vai à escola sem preparação; 2 . Avaliação formativa não é mais se não algumas pequenas provas que o professor faz para testar o aluno se está a estudar ou não; 3. A avaliação formativa é um método que um professor utiliza para ver até que ponto os alunos entenderam a matéria e para ajudar as notas caso sejam baixas.

Assim, a avaliação formativa na perspectiva dos alunos é uma prática cotidiana sob responsabilidade do professor 
antes, durante ou no fim da aula, com o objetivo de verificar, medir e classificar as capacidades do aluno em determinada matéria ou disciplina por meio de atividades desenvolvidas por escrito e/ou oral, em grupos ou individualmente.

\section{CONSIDERAÇÕES FINAIS}

À laia de conclusão, no geral, o referencial teórico adotado para organizar e sistematizar os procedimentos da avaliação da aprendizagem no âmbito da política de avaliação busca inspiração com vistas a desenvolver a aprendizagem do aluno, considerando a avaliação processo de reflexão e tomada de decisão com base nas suas produções; porém, a organização e procedimentos da avaliação pouco ou nada concorrem para a perspectiva construtiva da avaliação, aliás o modelo de avaliação é fortemente classificatório.

A análise das diretrizes da política de avaliação da aprendizagem e das concepções dos professores, formadores e dos alunos, futuros professores, mostra que os atores do processo de ensino e aprendizagem não foram tidos em conta em função das dificuldades de estruturas e de operacionalização da própria política de avaliação. Aponta-se, por exemplo, o posicionamento desfavorável, praticamente generalizado, dos professores e dos alunos relativamente à maneira como está distribuído o peso às avaliações das aprendizagens ao longo do processo de formação e no fim do ano letivo. Ainda é evidente que os Exames de Aptidão Profissional, embora aplicados apenas a alunos finalistas do curso, no final do ano letivo, minimizam o valor das atividades desenvolvidas pelos professores e dos próprios futuros professores ao longo da formação acadêmica.

A organização e os procedimentos da avaliação da aprendizagem parecem mostrar-se menos favoráveis à promoção da qualidade do ensino e da aprendizagem pela maneira como direcionam a prática da avaliação na sala de aula.

Reportando-se às escalas de avaliação das aprendizagens, é evidente que elas estão essencialmente fundamentadas em critérios numéricos classificatórios, e revelam, com 
isso, a maneira como se concebe a avaliação da aprendizagem no sistema de educação angolano. Ademais, a forma ou a configuração das avaliações impelem o aluno muito mais a se preocupar com a nota do que propriamente com a aprendizagem, dada a enfâse a ela atribuída durante e no fim do processo de formação. Os fundamentos da avaliação formativa fazem alusão à nota ou à classificação como uma das possibilidades para se encontrar vias que ajudem a desenvolver a progressão do aluno. Porém, o recurso à classificação ou a nota com fins de avaliação formativa deve estar muito bem esclarecido no âmbito dos objetivos que se pretendem alcançar.

A preocupação do futuro professor em interessar-se mais com a nota observa-se, sobretudo, quando as avaliações que se realizam primam pela classificação e quantificação da aprendizagem, colocando no topo a valorização da nota da Prova de escola. Isso também se verifica com base nos resultados da pesquisa, que assenta a avaliação formativa no centro da atribuição da nota, sendo que a maioria dos participantes da pesquisa (professores e alunos) mostra-se favorável às classificações das avaliações que se realizam continuamente.

O fato de os participantes da pesquisa demonstrarem não abrir mão à medição e à classificação das avaliações chamadas formativas configura a forma avaliativa na sala de aula, o que leva a concluir que as modalidades de avaliação na sala de aula, utilizadas pelos professores, são inteiramente somativas e não somativa e formativa.

A não concretização da política de avaliação da aprendizagem, pelos professores, pode ser uma dificuldade que alimente o questionamento sobre a qualidade da avaliação e do ensino, visto que as fragilidades da sua operacionalização não parecem estar unicamente associadas à falta de condições de trabalho e ao elevado número de alunos por turma. Supondo que os professores tivessem as condições de trabalho de que alegam, como seria a avaliação formativa? Importa referir, por um lado, que a dificuldade da prática da avaliação formativa também está ligada à necessidade de se desenvolverem formações de capacitação no campo da avaliação, dito de outro modo à formação acadêmica do 
professor, e à vontade política dos dirigentes. Por outro lado, muitas vezes as boas intenções dos professores não se concretizam, pois a eficácia da avaliação depende da mudança do formato da escola. O professor foi formado para um formato de escola excludente mesmo com aluno dentro dela.

A concretização da política de avaliação da aprendizagem instituída para a formação de futuros professores do $1^{\circ}$ Ciclo do Ensino Secundário é pobre em apontar uma avaliação para a aprendizagem construtiva e para os processos da avaliação formativa.

Não obstante haver a necessidade de revisão da organização e os procedimentos de avaliação na sala de aula à luz de fundamentos teóricos que sustentam a avaliação formativa, favorável à regulação da aprendizagem pelo próprio aluno, que possibilite adequar a avaliação à realidade sobre a qual ela incide, implicando com isso a tomada de consciência do professor sobre a democratização da aprendizagem, com vistas a promover o desenvolvimento do aluno sem que sejam desconsiderados fatores que, direta ou indiretamente, estão implicados no processo de ensino e aprendizagem; também é importante o professor não perder de vista que a organização ou a estrutura da escola pouco ajuda para a formação de alunos que venham a ser autônomos com pensamentos críticos úteis ao desenvolvimento da sociedade. Para tal, importa continuar as lutas e ir-se resistindo.

\section{REFERÊNCIAS}

ALLAL, Linda. Estratégias de avaliação formativa: concepções psicopedagógicas e modalidades de aplicação. In: ALLAL, Linda; CARDINET, Jean; PERRENOUD, Philippe (Org). A avaliação formativa num estudo diferenciado. Coimbra: Almedina, 1986. p. 175-194.

ALLAL, Linda; LOPEZ, Lucie Mottier. L'évaluation formative de 'apprentissage : revue de publications en langue française. In: Organisation de Coopération et Développement Économiques. L'évaluation formative: pour un meilleur apprentissage dans les classes secondaires. Paris: OCDE, 2005. p. 265-290.

ANGOLA. Lei n. 13/01, de 31 de Dezembro de 2001, I Série - N. 65. Lei de Bases do Sistema de Educação. Diário da República, Órgão Oficial da República de Angola, Luanda, 31 dez., 2001. 
ANGOLA. Ministério da Educação. Guia metodológico de avaliação das aprendizagens: fase de experimentação. Luanda: MED/Inide, 2003.

Reforma educativa: resumo das principais inovações nos sistemas de avaliação das aprendizagens. Luanda: MED/Inide, 2005a.

Metodologia de avaliação no contexto escolar. Luanda: MED/Inide, 2005b.

. Regulamento para os exames de aptidão profissional: formação de professores. Luanda: MED/Inide, 2005c.

Manual de apoio ao sistema de avaliação das aprendizagens $2^{\circ}$ ciclo do ensino secundário: reforma curricular. Luanda: MED/Inide, 2006.

. Reforma educativa: sistema de avaliação das aprendizagens para a formação de professores (Revisto). Luanda: MED/Inide, 2009a.

. Informação sobre a implementação do novo sistema de educação:

reforma educativa do ensino primário e secundário. Luanda:

MED/Inide, 2009b.

BARROS, Aidil de Jesus de; LEHFELD, Neid Aparecida de S. Projeto de pesquisa: propostas metodológicas. 17. ed. Petrópolis: Vozes, 1990.

DE LANDSHEERE, Gilbert. L'évaluation formative au service d'une école sans échec : Synthèse de la phase 1996-1997 de la recherche en pédagogie. Informations Pédagogiques, n. 38, p. 2-15, Déc. 1997. Disponível em: <http:// www.restode.cfwb.be/pgres/infoped/index3.htm>. Acesso em: 8 jan. 2013.

FERNANDES, Domingos. Para uma teoria da avaliação formativa. Revista Portuguesa de Educação, v. 2, n. 19, p. 21-50, 2006.

Avaliar para aprender: fundamentos, práticas e políticas. São Paulo: Unesp, 2009.

FREITAS, Luiz Carlos et al. Avaliação educacional: caminhando pela contramão. 3. ed. Petrópolis: Vozes, 2011.

HADJI, Charles. Ajudar os alunos a fazer a autorregulação de sua aprendizagem: por quê? Como? (Visando um ensino com orientação construtivista). Tradução de Laura Pereira. Pinhais: Melo, 2011.

NERI DE SOUZA, Francislê; COSTA, António Pedro; MOREIRA, António. Questionamento no processo de análise de dados qualitativos com apoio do software WebQDA. EDUSER: Revista da educação, Inovação na Educação com TIC, v. 3, n. 1, 2011. p.19-30. Disponível em: <http:// www.eduser.ipb.pt>. Acesso em: 3 dez. 2012.

PETITJEAN, Brigitte. Formes et fonctions des différents types d'évaluation. Pratiques de l'Évaluation, n. 44, p. 6-15, Déc. 1984.

SAMPIERI, Roberto Hernádez et al. Metodologia da pesquisa. 3. ed. Tradução de Fátima Murad, Melissa Kassner e Sheila Ladeira. São Paulo: Mc Graw-Hill, 2006.

SCALLON, Gérard. L'évaluation formative des apprentissages. Tome I: La réflexion, Québec, P.U.L., 1988, p. 155. Bulletin de la documentation collégiale, n. 4, Déc. 2010. Évaluation formative. p. 2. Disponível em: <http://www.cdc.qc.ca/bulletin/ bulletin4-evaluation-formative-dec-2010.pdf>. Acesso em: 14 jan. 2013. 
FRANCISCO CALOIA ALFREDO

Doutorando em Política Educativa na Universidade do Minho - Portugal. Integrante do Grupo de Trabalho: Formação de Professores e Práticas Pedagógicas da Pontifícia Universidade Católica (PUC-Campinas) franciscocaloia10@gmail.com

JUSSARA CRISTINA BARBOZA TORTELLA

Doutora em Educação pela Universidade Estadual de Campinas (Unicamp). Docente do Programa de Pós-Graduação em Educação Stricto Sensu da Pontifícia Universidade Católica (PUC-Campinas) atortella@uol.com.br 